\title{
Advanced Surface Enhancement
}

\author{
Alexander M. Korsunsky ${ }^{\mathbb{D}}$ \\ MBLEM, Department of Engineering Science, University of Oxford, Parks Road, Oxford OX1 3PJ, UK; \\ alexander.korsunsky@eng.ox.ac.uk; Tel.: +44-1865-273043
}

Received: 20 April 2020; Accepted: 23 May 2020; Published: 26 May 2020

\section{Introduction and Scope}

Ever since humans engaged in directed manufacturing activities to make tools and utensils, design decorative pieces of jewellery, build dwellings, and fabricate furnishings, they became concerned about surface properties. This included visual appearance, smoothness, tactile texture, wear resistance, and durability. Outstanding examples of the age-long attempts and achievements in modifying material surfaces to suit specific human needs can be seen in museum pieces that record mankind's material history.

With the advancement of technology and the development of engineering devices in which components have strictly defined structural or functional purposes, the role of surfaces became even more prominent. For example, in gear transmission systems, the smoothness and strength of contacting surfaces defines the system's performance, both in terms of efficiency and durability. In order to enhance the surfaces of engineered components and assemblies, a variety of means and methods have been proposed and implemented at industrial scales, including surface chemical treatment (e.g., carburising), coating, plastic deformation (shot peening or cold rolling), etc.

INCASE 2019 help in Singapore under the auspices of the Advanced Remanufacturing Technology Centre (ARTC) was devoted to the review, assessment, and discussion of the modern methods for surface enhancement that are in use in industry today, or are being elaborated and perfected at research and development organisations worldwide.

Five broad themes were chosen in the field of surface enhancement and included advances in measurement techniques, surface finishing, and conventional as well as novel processing methods for fatigue enhancement. As modern manufacturing rapidly evolves towards higher automation and the Industrie 4.0 paradigm, another key focus of INCASE2019 was placed on evaluating whether the surface enhancement community is adequately prepared for this transformation. With the active participation of industry and academia, and several keynote lectures from renowned experts in the field already planned, INCASE2019 has brought forth innovative ideas to address the challenges faced by the industry today, and provided inspiration for tomorrow's inventions.

A particular feature of the conference has been Industry Dialogue that was conducted by the conference chair in conversation with colleagues from companies and universities with the purpose of identifying the most urgent and demanding practical challenges that need to be addressed through joint coordinated efforts of the community.

\section{Contributions}

Seven articles have been published in the present Special Issue of Metals.

\subsection{Advanced Methods for Mechanical Finishing}

Articles on this theme included a study of ultra-high-speed magnetic abrasive surface micro-machining [1], which is a technique that is being progressively used to optimise surface accuracy and control the morphology of difficult-to-machine materials. Composite surface modification [2] was 
used to achieve simultaneously the benefits of surface peening and smooth finish. Vibropeening [3] is another technique that combines the advantages of introducing residual stress through peening with the reduction of surface roughness by polishing in a single processing step.

\subsection{Chemical Surface Layer Modification}

Surface layer modification often involves electromagnetic treatment, e.g., induction hardening, that induces phase transformation, such as the appearance of martensite, or chemical processes, such as nitriding or carburizing. Conventional gas nitrocarburising has been used to increase strength and productivity of the automotive crankshafts. Potential-controlled nitriding processing has been developed recently to control the crystal structure of the nitride compound layer. The results that can be achieved using this treatment have been reviewed in [4].

\subsection{Laser Surface Modification}

Laser-induced periodic surface structures (LIPSS) arise due to the intricate interaction between illuminating photons and the substrate material that may lead to material ablation, or other mechanisms of mass transport across the surface. As a consequence, aligned ripples with sub-micron period may form, or conical microstructures may form upon further treatment that can be used to modify the frictional and wetting properties of the surface. In study [5], treated areas at the surface of AA2024-T4 aluminium alloy were evaluated using focused ion beam (FIB)-scanning electron microscopy (SEM) imaging and sectioning, energy-dispersive X-ray (EDX) spectroscopy, atomic force microscopy (AFM), and confocal laser profilometry, to reveal the surface profiles and subsurface structure of the laser-treated surfaces.

\subsection{Surface Metrology}

Surface characterisation plays an important role in the enhancement treatment processes. For example, surface topography measurement in mirror-finished products can be time-consuming and difficult to integrate into manufacturing processes. Study [6] reports the use of sub-micron surface fluctuation in combination with light-scattering effects and image processing to perform surface texture analysis. A non-contact surface inspection system using a fringe-patterned illumination method is proposed. In study [7], surface acoustic waves (SAW) were used to quantify acoustic nonlinearity and mechanical properties of Al6061 alloy components following different heat treatments.

\section{Conclusions and Outlook}

A variety of connected topics have been compiled in the present Special Issue of Metals, providing an overview of recent developments in different aspects of advanced surface enhancement. It is the editors' hope that this Special Issue will serve as a starting point for future discussions and scientific debate on challenging topics.

Conflicts of Interest: Guest Editor co-authored one of the papers included in this Special Issue. He declares that the handling and reviewing of this paper was carried out without his involvement, fully independently by MDPI editorial staff.

\section{References}

1. Yin, C.; Wang, R.; Kim, J.; Lee, S.; Mun, S. Ultra-High-Speed Magnetic Abrasive Surface Micro-Machining of AISI 304 Cylindrical Bar. Metals 2019, 9, 489. [CrossRef]

2. Fu, H.; Liang, Y. Study of the Surface Integrity and High Cycle Fatigue Performance of AISI 4340 Steel after Composite Surface Modification. Metals 2019, 9, 856. [CrossRef]

3. Chan, W.; Ahluwalia, K.; Gopinath, A. Parametric Study of Fixtured Vibropeening. Metals 2019, 9, 910. [CrossRef] 
4. Yamada, Y.; Hirohito, E.; Takahashi, K. Influence of Crystal Structure of Nitride Compound Layer on Torsion Fatigue Strength of Alloy Steel. Metals 2019, 9, 1352. [CrossRef]

5. Salimon, I.; Mailis, S.; Salimon, A.; Skupnevskiy, E.; Lipovskikh, S.; Shakhova, I.; Novikov, A.; Yagafarov, T.; Korsunsky, A.M. FIB-SEM Investigation of Laser-Induced Periodic Surface Structures and Conical Surface Microstructures on D16T (AA2024-T4) Alloy. Metals 2020, 10, 144. [CrossRef]

6. Fu, S.; Cheng, F.; Tjahjowidodo, T. Surface Topography Measurement of Mirror-Finished Surfaces Using Fringe-Patterned Illumination. Metals 2020, 10, 69. [CrossRef]

7. Jun, J.; Seo, H.; Jhang, K. Nondestructive Evaluation of Thermal Aging in Al6061 Alloy by Measuring Acoustic Nonlinearity of Laser-Generated Surface Acoustic Waves. Metals 2020, 10, 38. [CrossRef]

(C) 2020 by the author. Licensee MDPI, Basel, Switzerland. This article is an open access article distributed under the terms and conditions of the Creative Commons Attribution (CC BY) license (http://creativecommons.org/licenses/by/4.0/). 